\title{
Hybrid zones of Heliconius butterflies in Panama and the stability and movement of warning colour clines
}

James Mallet*
Department of Zoology, University of Texas, Austin, Tx. 78712, U.S.A.

Heliconius erato and $\boldsymbol{H}$. melpomene are warningly coloured tropical butterflies that show mimetic covariation throughout the neotropics. Central American, West Colombian, and North Colombian colour pattern races of both species meet and form hybrid zones in Panama. These hybrid zones were sampled along a transect. The major colour pattern changes are determined by three alleles at a single locus in each species. There is no evidence for hybrid breakdown or mating incompatibility between any of the phenotypes in Panama, and local genotypic frequencies are not significantly different from Hardy-Weinberg expectation.

I simulated a single-locus, two-allele warning colour hybrid zone (cline) with dominance. Predator selection on warning colour patterns was assumed to be frequency-dependent, so that, at any point in the cline, a rare phenotype has lower fitness than a common phenotype. Simulation shows that such a cline rapidly reaches a stable slope. Since the model does not depend on selection caused by the abiotic environment, the cline is positionally unstable. Even if the two phenotypes are equally fit "dominance drive" tends to increase the area in which the dominant allele is present. Differences in fitness of the phenotypes and density gradients can also cause cline movement. Hybrid zone movement might either be rapid enough to obliterate patterns that were formed in Pleistocene refugia, or so slow as to make secondary contact a requirement for the existence of hybrid zones. A third possibility is that local variations in population density will normally prevent hybrid zone movement, even if this is potentially rapid. Better estimates of dispersal and selection are needed to resolve this issue.

\section{INTRODUCTION}

Many groups of closely related taxa are distributed in patchwork patterns, with their ranges abutting. These "parapatric" forms are often separated by narrow zones of hybridisation. For the purposes of this paper, I define hybridisation as the process of obtaining offspring (hybrids) in natural or artificial crosses between genetically distinct strains, and hybrid zone as a narrow zone of genetic change (where natural hybrids occur) between the ranges of two parapatric, genetically distinct forms. These definitions are useful because they are based on the phenomena themselves rather than on the unknown causes of the phenomena. I use neither history (Mayr, 1970: 69), nor fitness or stability (e.g., Endler, 1977; Barton, 1979; Barton and Hewitt, 1981) to define hybridisation and hybrid zones.

* Present address: Galton Laboratory, Department of Genetics and Biometry, University College of London, 4 Stephenson Way, London NW1 $2 \mathrm{HE}$.
Species of the butterfly genus Heliconius often have large numbers of colour-pattern races with parapatric distributions, connected by hybrid zones (Brown and Mielke, 1972; Brown et al., 1974; reviewed by Brown, 1976; 1982; Turner, 1982). The standard explanation has been that this raciation occurred in allopatric Neotropical refugia during Pleistocene dry periods (Turner, 1965; Brown et al., 1974; Brown, 1982; Turner, 1982). Recently, a number of authors have suggested that parapatric differentiation is equally consistent with the available evidence from Heliconius (Endler, 1977; 1982; White, 1978; Benson, 1982). Much of this work has centred on Heliconius erato and $H$. melpomene, which are common, well collected, and have very well-known biology (Emsley, 1964; Brown, 1981; Turner, 1981). These two species have phenomenal parallel geographic variation in colour pattern, which provides one of the best pieces of evidence for the existence of mimicry (see Turner, 1982). Major colour pattern differences between races of both species are usually controlled by a few Men- 
delian factors (Turner, 1982; Sheppard et al., 1985). Both species are distasteful to birds, and their colour patterns are almost certainly selected for warning coloration and Müllerian mimicry (Brower et al., 1963; Brower and Brower, 1964; Benson, 1972). Widths of hybrid zones in $H$. erato and $H$. melpomene have been reported to be 10 $200 \mathrm{~km}$ wide (Benson, 1982; Brown and Mielke, 1972; Turner, 1971 a), but detailed transects have not been made, and the genetics of the zones is often not known. The lack of detailed work in Heliconius hybrid zones makes it hard to guess how they originated and how they are maintained.

Three races of $H$. erato meet in Panama (See fig. 1): (1) a "Central American" race which has a red forewing band and a yellow hindwing bar (distributed from Northern Mexico south to Eastern Panama); (2) a "North Colombian" race which is similar to the Central American race but which lacks the yellow bar (distributed from the Guianas east through Venezuela to North-Central Colombia); and (3) a "West Colombian" race which is also similar to the Central American race, except that its yellow bar is expressed on the undersurface only (distributed in Colombia west of the Western Cordillera of the Andes). For simplicity, the currently accepted scientific names of the races are not used here, but are given in table 1. There are also minor colour pattern differences between the races (see Results). The distributions of these races are shown in fig. 2. Heliconius melpomene has an overall pattern of racial variation similar to that of $H$. erato (see fig. 1 for phenotypes), which is almost certainly due to Müllerian mimicry (Brown et al., 1974). The minor color pattern elements in $H$. melpomene also track their analogues in $H$. erato. The genetics of some of the colour pattern differences between these races has been studied by Sheppard et al. (1985) and Mallet et al. (unpubl.). In both species the presence of the hindwing yellow bar is determined by a single allele which is almost completely recessive to absence of yellow, although a shadow can be seen in the black pigment of the underside bar region of heterozy-

Table 1 Trinomial nomenclature of Heliconius races in Panama hybrid zones

\begin{tabular}{lll}
\hline $\begin{array}{l}\text { Name of race used } \\
\text { in this paper }\end{array}$ & $\begin{array}{l}\text { Heliconius } \\
\text { erato } \\
\text { subspecies }\end{array}$ & $\begin{array}{l}\text { Heliconius } \\
\text { melpomene } \\
\text { subspecies }\end{array}$ \\
\hline $\begin{array}{l}\text { Central American } \\
\text { West Colombian } \\
\text { North Colombian }\end{array}$ & $\begin{array}{l}\text { petiverana } \\
\text { venus } \\
\text { hydara }\end{array}$ & $\begin{array}{l}\text { rosina } \\
\text { vulcanus } \\
\text { melpomene }\end{array}$ \\
\hline
\end{tabular}

Source: Brown $(1976 ; 1979)$ gotes (shown schematically in fig. 1). In $H$. melpomene, the West Colombian yellow bar (on underside only) is dominant to the Central American bar (on upper and underside), and recessive to lack of bar, but the inheritance of the West Colombian pattern is not known for $H$. erato.

The purposes of this study were to obtain data on the shapes, widths, and genetics of hybrid zones of $H$. erato and $H$. melpomene in Panama, and to investigate the fitnesses of hybrids and the stability of interactions in the zones.

\section{MATERIALS AND METHODS}

The study was carried out in three parts: (1) phenotypes of $H$. erato from the hybrid zone were intercrossed to determine the inheritance of colour pattern; (2) samples of $H$. erato and $H$. melpomene were taken along a transect through the hybrid zones; and (3) a simulation model of a hybrid zone was constructed and used to analyse the genetic data.

Laboratory crosses of $\mathrm{H}$. erato. Since the known genetics of hybridisation had been deduced from allopatric crosses (e.g., Mexico $\times$ Trinidad), and since some of the genetics were not known for $H$. erato, I performed crosses of $H$. erato using hybrid zone stock. Adults were kept in outdoor insectaries in Panama City, using techniques given by Turner (1974). The eggs were separated individually and their hatch rate recorded. Larvae were reared to maturity, and the adults were scored for the following: sex; yellow hindwing bar (presence, shadow or absence); yellow bar type if present (Central American or West Colombian); upperside blue iridescence (scale 0-1); markedness of distal white fringes (scale 0-1); and size (forewing length).

Wild-mated female parents were collected in Garachiné for broods PA1-PA2; and in Tortí for broods PA3-PA6 (table 2). They were allowed to deposit eggs until their first progeny began to enclose from the pupa. Females of these progeny, and females reared from field-collected larvae were then mated to field-collected males chosen to test hypotheses of colour pattern inheritance (table 2: broods PA7-PA12). The following parents in table 2 were reared from earlier broods: the female parent of PA8 is from PA2; female parents of PA10, PA11 and PA12 are from brood PA1. The female parent of PA7 was reared from a larva collected in Puerto Obaldía, that of PA9 from a larva collected in Piriatí. A single male from Tortı fathered broods PA8, PA9, PA11, and PA12, and the male parents of PA7 and PA10 were also from Tortí. 


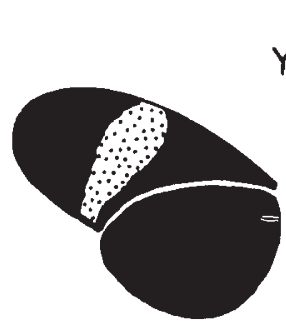

under

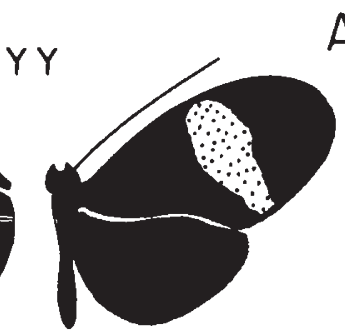

upper
A
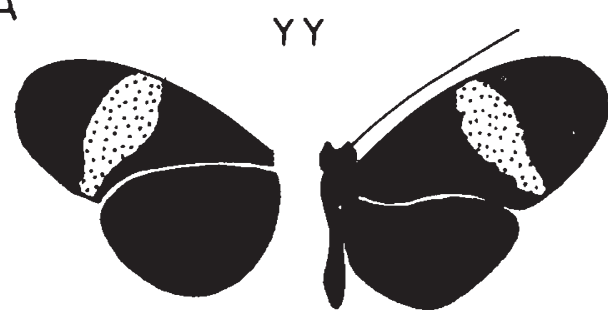

North Colombian
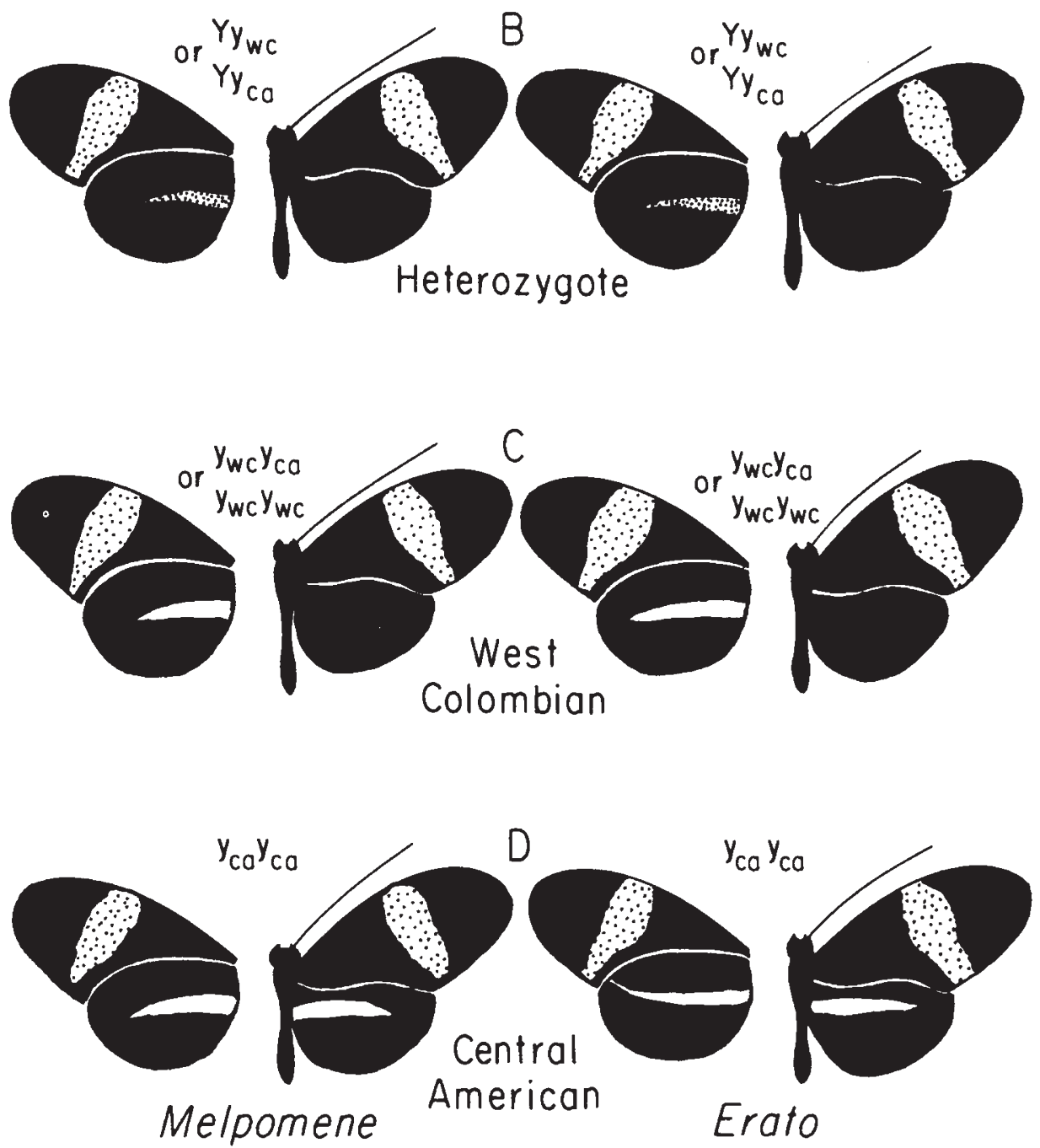

Figure 1 Phenotypes and genotypes of Heliconius melpomene and $H$. erato found in the Panama hybrid zone. The phenotypes correspond to races as follows: $A$, North Colombian race. B, Heterozygote between West Colombian or Central American, and North Colombian races. $C$, West Colombian race. $D$, Central American race. Genotypes shown conform to the results obtained in crosses. 


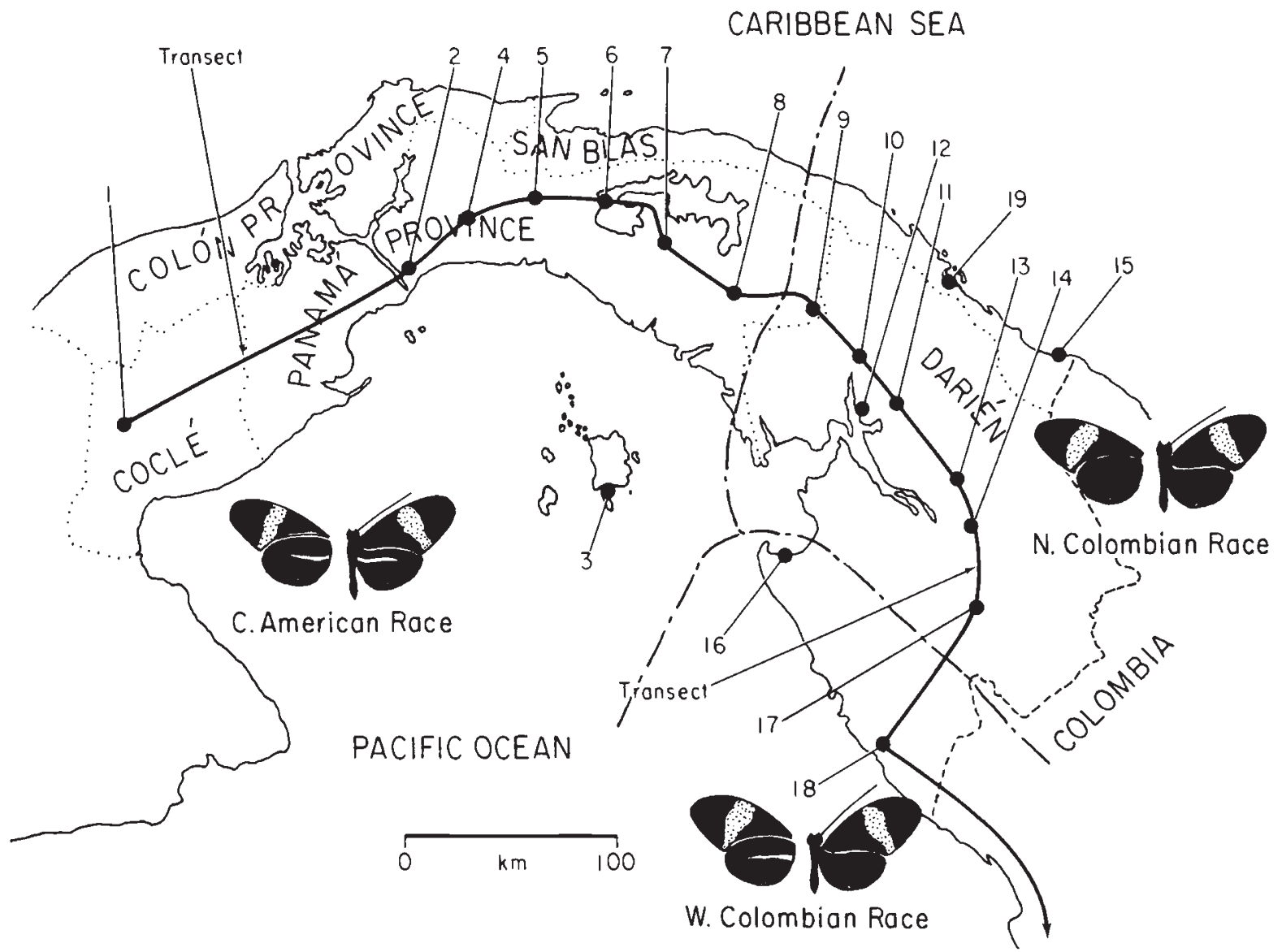

Figure 2 Distribution of colour pattern races of $H$. erato in Panama, showing sample sites and transect. See table 4 for exact locations and names of sample sites.

Heliconius females are almost monandrous (Boggs, 1979), and show sperm precedence for their last mating (L. Gilbert, pers. comm.), so it was possible to deduce the wild male parents of broods PA1PA6 from the progeny distribution. The simplest genetic hypothesis that is consistent with all the data of table 2 was proposed and is given in fig. 1. The genotypes of parents in table 2 were then deduced from their own phenotypes (if available) and from the phenotypes of their progeny and grand-progeny. For instance, one Garachiné parent of PA1 must have carried a $y_{c a}$ allele since female offspring of brood PA1 produced $D$ phenotypes in broods PA10 and PA12 (table 2), although there were no $D$ phenotypes in the population sample from Garachiné (table 4) or in brood PA1. The genetic hypothesis was tested by means of a $X^{2}$ goodness of fit test.

Field sampling of hybrid zones. I collected samples at 14 sites along a bent transect that stretched from Panama City eastwards to Darién, and turned south into Western Colombia (fig. 2). Four addi- tional samples from sites away from the transect were also collected. Precise collecting locality data is given in table 4. At many sites I sampled a number of subsites to determine the constancy of allele frequency between subsites. Subsites were less than $10 \mathrm{~km}$ apart, while separate sites were more than $10 \mathrm{~km}$ apart, usually about $15-30 \mathrm{~km}$ apart. When an individual Heliconius was seen it was chased as rapidly as possible until it either was caught or escaped over terrain that precluded further chase. The phenotypes were scored as they were in the crosses. Genotypic and allelic frequencies were calculated for each site. At some sites, especially in $H$. melpomene, there were three alleles segregating. Using a maximum likelihood method (Appendix 1) which assumes Hardy-Weinberg equilibrium (see Results) the frequencies of all three alleles were estimated.

Model of warning colour evolution in a hybrid zone. Most models of clines stabilised by gene flow and selection depend on there being a constant environmental "step" or "ramp" (Felsenstein, 1976; Endler, 1977), so that different alleles are 
Table 2 Broods of Heliconius erato

\begin{tabular}{|c|c|c|c|c|c|c|}
\hline \multirow{2}{*}{$\begin{array}{l}\text { Brood } \\
\text { number }\end{array}$} & \multirow{2}{*}{$\begin{array}{l}\text { Male } \\
\text { parent }\end{array}$} & \multirow{2}{*}{$\begin{array}{l}\text { Female } \\
\text { parent }\end{array}$} & \multicolumn{4}{|c|}{ Progeny phenotypes (males/females) } \\
\hline & & & A & B & $\mathrm{C}$ & $\mathrm{D}$ \\
\hline \multicolumn{7}{|c|}{ A: Progeny of females mated by unknown wild males } \\
\hline \multirow{2}{*}{ PA1 } & $Y y_{w c}$ & C $y_{w c} y_{c a}$ & & \multirow{2}{*}{$13 / 13$} & \multirow{2}{*}{$26 / 15$} & \\
\hline & $Y y_{c a}$ & $\mathrm{C} y_{w c} y_{w c}$ & & & & \\
\hline PA2 & $Y Y$ or $Y y_{-}$ & A $Y Y$ & $0 / 1$ & & & \\
\hline PA3 & $Y Y$ or $Y y$ & A $Y Y$ & $2 / 3$ & & & \\
\hline PA4 & $y_{c a} y_{c a}$ & $\mathrm{D} y_{c a} y_{c a}$ & & & & $31 / 34$ \\
\hline PA5 & $y_{c a} y_{c a}$ & A $Y Y$ & & $15 / 28$ & & \\
\hline PA6 & $Y y_{c a}$ & $\mathrm{~B} Y y_{c a}$ & $4 / 6$ & $9 / 7$ & & $4 / 8$ \\
\hline \multicolumn{7}{|c|}{ B: Progeny of females which were mated with known males } \\
\hline PA7 & $\mathrm{D} y_{c a} y_{c a}$ & A $Y Y$ & & $43 / 29$ & & \\
\hline PA8 & В $Y y_{c a}$ & A $Y Y$ & $31 / 24$ & $23 / 36$ & & \\
\hline PA9 & В $Y y_{c a}$ & $\mathrm{D} y_{c a} y_{c a}$ & & $7 / 19$ & & $6 / 12$ \\
\hline PA10 & $\mathrm{D} y_{c a} y_{c a}$ & C $y_{w c} y_{c a}$ & & & $25 / 38$ & $18 / 24$ \\
\hline PA11 & В $Y y_{c a}$ & B $Y y_{w c}$ & $8 / 5$ & $18 / 14$ & $13 / 8$ & \\
\hline PA12 & B $Y y_{c a}$ & $\mathrm{C} y_{w c} y_{c a}$ & & $7 / 10^{*}$ & $5 / 5$ & $8 / 7$ \\
\hline
\end{tabular}

Notes: Observed phenotypes of parents are shown with their genotypes as deduced from the results of the crosses. A total of 662 progeny are included, three individuals were unscorable

* Two of these individuals had only fragments of a shadow bar on the underside of the hindwing

favoured on either side of a fixed zone of changing selection. However, there were no obvious environmental changes in the region of the Panama hybrid zones. In fact the "environment" of each butterfly with respect to warning colour evolution is likely to be a set of predators that have learned the colour patterns of other noxious butterflies. A new model, similar but not identical to that of chromosomal evolution (Barton, 1979), was needed in which a morph is selected against at low frequencies (because predators do not recognise the butterfly as inedible), is neutral at some intermediate critical frequency, and is the superior morph at high frequencies (because predators have learned the common pattern). To my knowledge, this sort of model has only been discussed in very general terms (Hadeler, 1976; Stokes, 1976) and it was therefore necessary to construct a specific model for warning colour pattern evolution.

I performed computer simulations to examine the dynamics of a two-allele single-locus warning colour cline, with the following assumptions: (1) One diploid species only is modeled. It is obvious that a second species added to the first would behave identically to the first species if their dispersal rates were equal and if selection for colour pattern was the same for both species. Since disper- sal rates are known for $H$. erato (Mallet, 1984, 1985) and not for $H$. melpomene, the addition of a second species would at this stage be more confusing than useful. $H$. erato was always more common than $H$. melpomene in Panama (table 4), so a cline in $H$. erato is likely to be influenced mainly by its own local gene frequencies. The model is therefore a model of $H$. erato alone, the expectation being that $H$. melpomene should follow $H$. erato rather closely. (2) A single gene determines colour pattern differences. This assumption is supported by the results of crossing hybrid zone phenotypes (see Results). (3) Selection acts on phenotypes. I have assumed that in the $150 \mathrm{~km}$ hybrid zone of $H$. erato (see Results), predators cannot tell the phenotypes $A$ and $B$ (fig. 1) apart. This corresponds with what a human predator can distinguish in flight, and is suspected to be the case for birds. This is equivalent to assuming that one allele is dominant. (4) Selection is frequencydependent so that the more common a phenotype, the less it is selected against. Maximal selection against the dominant phenotype is given by $s_{1}$, against the recessive phenotype by $s_{2}$. This comes from the expected behaviour of predators towards warningly coloured prey, and is supported by the monomorphism of $H$. erato in most areas, and the exact Müllerian mimicry with $H$. melpomene. In 
the model selection is given by the equations:

$$
\begin{aligned}
f_{A A}^{\prime} & =f_{A A}\left(1-s_{1} f_{a a}\right) / W_{m} \\
f_{A a}^{\prime} & =f_{A a}\left(1-s_{1} f_{a a}\right) / W_{m} \\
f_{a a}^{\prime} & =f_{a a}\left\{1-s_{2}\left(f_{A A}+f_{A a}\right)\right\} / W_{m}
\end{aligned}
$$

where $f_{A A}, f_{A A}^{\prime}$, etc., represent the frequencies of the homozygous dominant genotype before and after selection, $s_{1}$ and $s_{2}$ are selection coefficients, and $W_{m}$ is the mean fitness obtained by summing the numerators. No frequency-independent or heterotic selection is incorporated. The frequencydependence used is linear. I have also used exponential models, for example so that:

$$
f_{A A}^{\prime}=f_{A A}\left\{1-s_{1} 1000^{-\left(f_{A A}+f_{A a}\right)}\right\} / W_{m} \cdots \text { etc. }
$$

Simulations show that, using this exponential selection function, when $m=0 \cdot 1$, and $s_{1}=s_{2}=0 \cdot 1$, cline movement speed is 73 per cent of the speed of movement in the linear model; when $m=0.9$ and $s_{1}=s_{2}=0.9$, cline movement speed is 81 per cent of the equivalent speed using linear selection. This is convenient for comparison with real clines, because the exact form of frequency-dependence in nature is almost certainly not linear. The linear model approximates a variety of types of frequency dependence. (5) Selection is assumed to be perfectly "soft" (Wallace, 1968) so that the population sizes are independent of gene frequencies. This means that deme sizes of $H$. erato are mainly determined by density-dependent factors rather than selection on colour pattern. This is likely: in many areas I visited carrying capacity was apparently reached, and hostplants were defoliated by $H$. erato larvae. Also, selection on colour pattern phenotypes is probably weak enough to cause little change in adult densities. (6) Genetic drift is assumed to be negligible. This assumption is supported for $H$. erato by the following: (i) the lack of subdivision within subsites as indicated by approximate Hardy-Weinberg equilibrium; (ii) the similarities of gene frequencies between different subsites; (iii) the overall smoothness of the $150 \mathrm{~km}$ cline. (7) Random mating is assumed. This assumption seems likely as a first approximation (see Results), but should be tested in the field. (8) A one-dimensional cline is modeled. Although this may seem rather unrealistic, it represents a transect at right angles to a real, two-dimensional cline (Bazykin, 1969; Barton, 1979). A stepping-stone population structure is assumed, with migration between adjacent demes occurring at a rate $m / 2$ in each direction. In some simulations $m$ was allowed to vary spatially in order to model the effects of a density gradient along the cline. The parameter $m$ is equivalent to the one-dimensional variance of the progeny distribution in a continuous model. Thus $m=\sigma^{2}$, where $\sigma$ is the rootmean-square axial dispersal distance ( $l$ of Endler, 1977).

Two other technical assumptions were made: (9) The model has discrete generations. The order of processes simulated for each deme is (i) random mating, (ii) migration, (iii) selection, (iv) random mating again, etc. (10) The simulations start with secondary contact, so that if there are $N$ demes in total, demes 1 to $N / 2$ are fixed for allele $a$; and demes $(N / 2)+1$ to $N$ are fixed for allele $A$.

\section{RESULTS}

Laboratory crosses. The broods of $H$. erato conform to results expected if the yellow hindwing bar phenotypes are controlled by three alleles at a single gene (table 2). The underside West Colombian yellow bar is dominant to the Central American bar, itself expressed on both surfaces of the hindwing. Both yellow hindwing bar phenotypes are recessive to all-black hindwing. The allelic dominance relations can be expressed as $Y>y_{w c}>y_{c a}$. However, because $Y y$ heterozygotes can be detected as a shadow, there are four phenotypes discernible: $A(Y Y), B\left(Y y_{w c}\right.$ or $\left.Y y_{c a}\right)$, $C\left(y_{w c} y_{w c}\right)$ or $\left(y_{w c} y_{c a}\right)$ and $D\left(y_{c a} y_{c a}\right)$. These relationships are pictured in fig. 1. Although the phenotypic frequencies of one brood (table 2: PA10) do not conform to this scheme $\left(X_{1}^{2}=4 \cdot 2\right.$, $P<0 \cdot 05)$, a brood this aberrant is expected in these 12 broods $\left(X_{10}^{2}=15 \cdot 0, \mathrm{~ns}\right)$. Minor colour patterns and size are clearly brood-dependent and are therefore genetically controlled, but have a more complex (probably polygenic) inheritance than the yellow hindwing bar.

The results show that the inheritance of the West Colombian and Central American yellow hindwing bars in $H$. erato is similar to that found for $H$. melpomene (Mallet et al., unpubl.). I have therefore used the same allelic symbols for both species (fig. 1), without meaning to imply homology of the genes for these two species. The $Y$ locus studied here in $H$. erato probably corresponds to the $C r$ locus of Sheppard et al. (1985); in $H$. melpomene, my $Y$ locus probably corresponds to the $Y b$ locus of the same authors.

There was no evidence for any hybrid breakdown: seven of the broods had at least one heterozygous parent, and since even the homozygotes were taken from the hybrid zone, most parents of the broods presumably had hybrid ancestors. No lack of fertility was observed in any 
of the broods, which produced large numbers of eggs (the small numbers in PA2-PA3 are due to death of the parents while I was away), and there was a 98 per cent hatch rate of eggs (Mallet, 1984). Two broods had sex ratios that were significantly different from $1: 1$ (PA5, $X_{1}^{2}=3 \cdot 9, P<0 \cdot 05$; PA9, $\left.X_{1}^{2}=6 \cdot 4, P<0.025\right)$ and there was slight sex ratio heterogeneity between the broods $\left(X_{12}^{2}=23 \cdot 0, P<\right.$ $0 \cdot 05)$. However, there was no significant deviation from a $1: 1$ sex ratio overall $\left(X_{1}^{2}=1 \cdot 17, \mathrm{~ns}\right)$ because broods deviated in opposite directions. There were no obvious premating incompatibilities: healthy males immediately mated with any virgin females presented to them. This hybrid viability concurs with other interracial hybridisation studies in Heliconius (Turner and Crane, 1962; Sheppard, 1963; Turner, 1972; Sheppard et al., 1985).

Field samples of hybrid zones. To test for subsite differentiation, the two yellow hindwing alleles $\left(y_{w c}\right.$ and $y_{c a}$ ) were lumped, so that exact gene frequencies could be obtained from the frequencies of the genotypes ( $Y Y, Y y$ and $y y)$. Although one site, Cañazas, had significant subsite differentiation for $H$. erato $\left(X_{2}^{2}=9 \cdot 3, P<0 \cdot 01\right)$, a site this extreme is expected in the 9 sites for $H$. erato $\left(X_{11}^{2}=16 \cdot 6\right.$, ns, see Table 3); overall there is no evidence for subsite differentiation in either $H$. erato or $H$. melpomene. These results show that dispersal is usually sufficient to unite subsites to a common gene frequency (table 3). Alternative explanations of heterosis, or frequency-dependent selection favouring rare alleles, seem very unlikely to maintain polymorphisms in subsites, since the colour pattern alleles are fixed throughout the rest of their ranges, as is expected for warning color selection (Turner et al., 1979; Turner, 1982). There were no significant deviations from Hardy-Weinberg proportions at 24 subsites for $H$. erato or at seven subsites for $H$. melpomene (Mallet, 1984). This result agrees with those of Turner $(1971 a)$ on $H$. melpomene in Suriname, and provides field evidence (somewhat weak-see Lewontin and Cockerham, 1959) for lack of hybrid breakdown and for random mating throughtout the hybrid zones. In contrast, Descimon and Mast de Maeght (1984) found hybrid deficits in a hybrid zone between $H$. erato and the closely-related species H. himera.

The numbers of individuals of different phenotypes at each site are given in Table 4 . The phenotypic frequencies of samples along the transect are shown in fig. 3 , lumping the very similar dark hindwing morphs $A$ and $B$ (fig. 1 ). The gene frequencies are given in fig. 4. Figs. 3
Table 3 Allele frequencies within subpopulations

\begin{tabular}{|c|c|c|c|}
\hline \multirow[b]{2}{*}{ Site } & \multirow{2}{*}{$\begin{array}{l}\text { Subsite } \\
\text { number }\end{array}$} & \multicolumn{2}{|c|}{ Number of alleles } \\
\hline & & $y$ & $Y$ \\
\hline \multicolumn{4}{|l|}{ A: H. erato } \\
\hline \multirow[t]{2}{*}{ Cd. Panamá } & 1 & 34 & 0 \\
\hline & 2 & 39 & 1 \\
\hline \multirow[t]{2}{*}{ Is. Rey } & 1 & 21 & 3 \\
\hline & 2 & 22 & 6 \\
\hline \multirow{3}{*}{ El Llano } & 1 & 24 & 0 \\
\hline & 2 & 20 & 0 \\
\hline & 3 & 38 & 4 \\
\hline \multirow[t]{3}{*}{ Cañazas } & 1 & 29 & 53 \\
\hline & 2 & 25 & 27 \\
\hline & 3 & 32 & 96 \\
\hline \multirow{2}{*}{ Qu. Mono } & 1 & 7 & 39 \\
\hline & 2 & 0 & 20 \\
\hline \multirow[t]{2}{*}{ Metetí } & 1 & 8 & 64 \\
\hline & 2 & 1 & 25 \\
\hline \multirow[t]{2}{*}{ Yaviza } & 1 & 4 & 30 \\
\hline & 2 & 4 & 50 \\
\hline \multirow{2}{*}{ Pu. Obaldia } & 1 & 5 & 37 \\
\hline & 2 & 6 & 46 \\
\hline \multirow[t]{2}{*}{ Guayabo } & 1 & 33 & 27 \\
\hline & 2 & 16 & 14 \\
\hline \multicolumn{4}{|c|}{ B: H. melpomene } \\
\hline \multirow[t]{3}{*}{ Cañazas } & 1 & 31 & 13 \\
\hline & 2 & 16 & 10 \\
\hline & 3 & 38 & 22 \\
\hline
\end{tabular}

and 4 show that the hybrid zone between the Central American and North Colombian race of $H$. erato is a rather smooth cline whose major change in frequency occurs between $145 \mathrm{~km}$ and $215 \mathrm{~km}$ of the transect (hereafter referred to as the $150 \mathrm{~km}$ hybrid zone), near the Panama-Darien provincial boundary. The width, $w=1 /(\max$. gradient $)$, is about $80 \mathrm{~km}$. The width of the hybrid zone between the North Colombian and West Colombian races of $H$. erato cannot be calculated due to lack of samples, but there is a sharp difference between $340 \mathrm{~km}$ and $375 \mathrm{~km}$ in the frequency of $y_{w c}$ alleles, suggesting that this hybrid zone is at least as steep as the first one. The hybrid zones of $\mathrm{H}$. melpomene are on average much broader, $180 \mathrm{~km}$ or more wide, but these clines are much less smooth than those of $H$. erato, with some sharp changes in frequency which are of steeper gradient than the $H$. erato clines.

One non-transect site is of particular interest, that of the Pacific Isla del Rey (table 4). No $H$. melpomene were present on this arid island, but $H$. erato was present and polymorphic for $Y$ and $y_{c a}$. The last time this arid member of the Perlas Islands was connected to the mainland was in the last Pleistocene dry period about 12,000 years ago (MacArthur, 1972), so either the hybrid zone was present during the supposed refugial era, or 
Table 4 The numbers of individuals of different phenotypes at each site

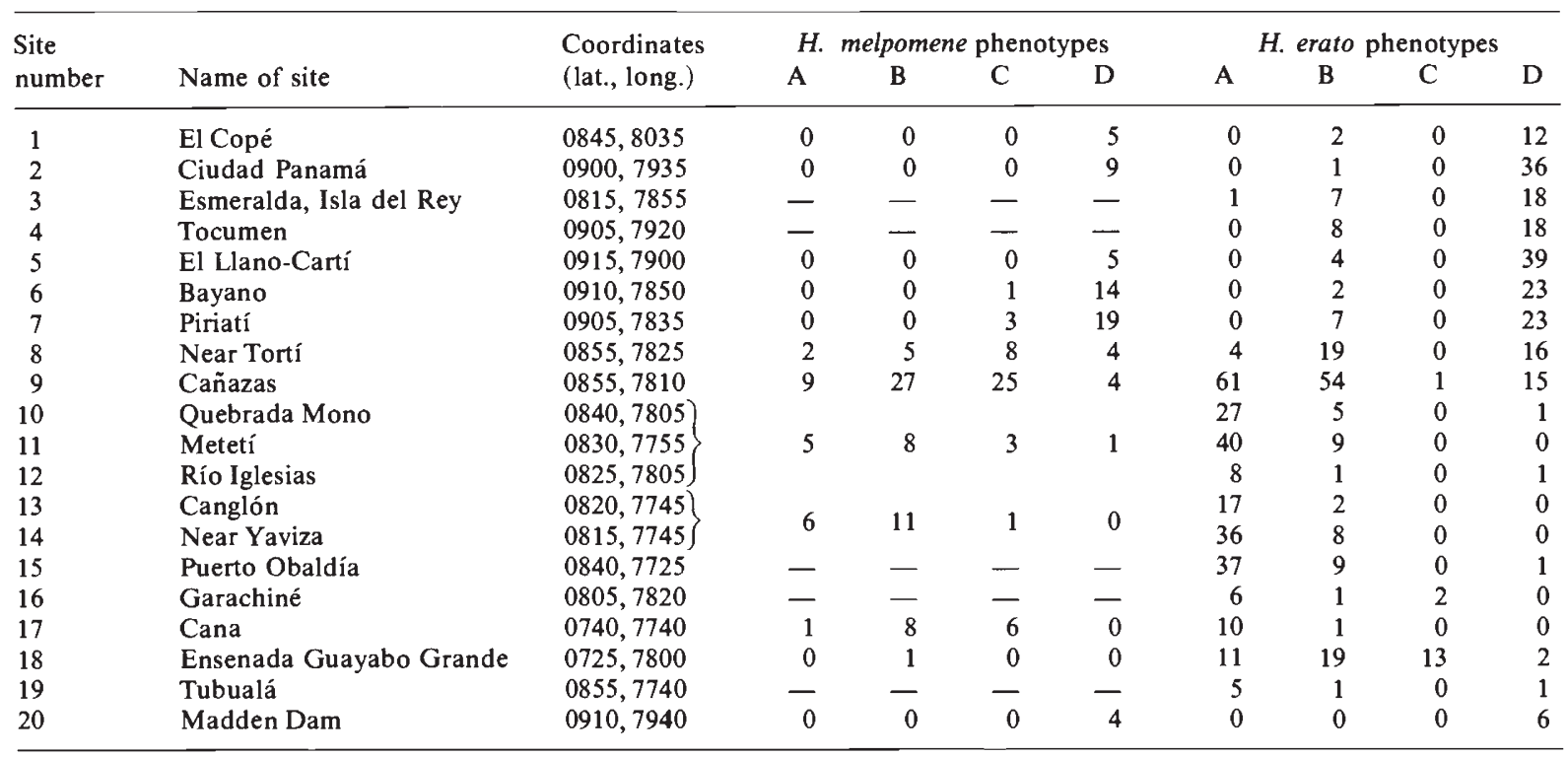

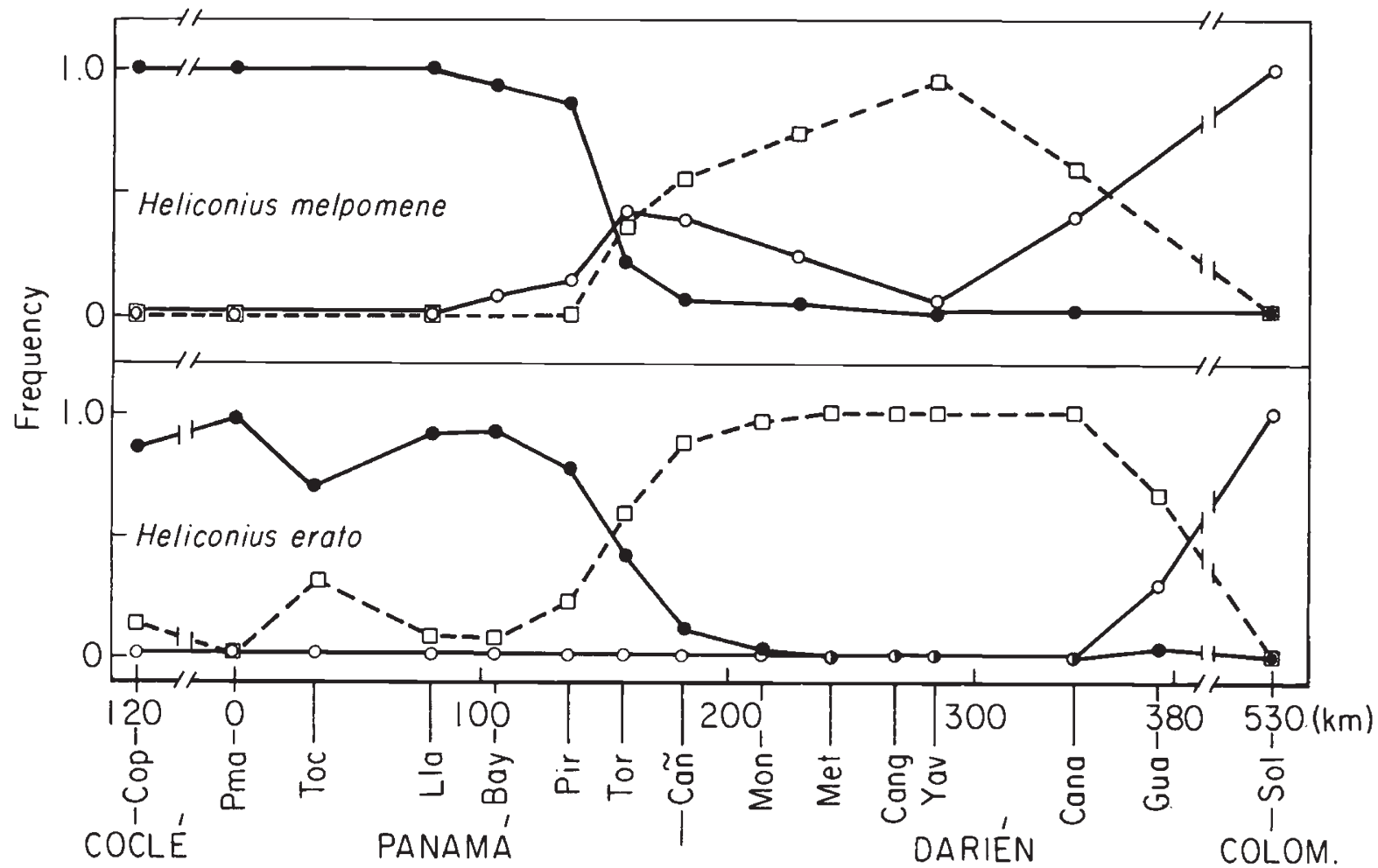

Figure 3 Phenotype frequencies along the transect. Open squares, black hindwing (phenotypes $A$ and $B$ combined). Open circles, West Colombian hindwing bar (phenotype $C$ ). Closed circles, Central American yellow hindwing bar (phenotype $D$ ). (Data from table 4). 




Figure 4 Frequencies of yellow hindwing bar alleles along the transect. Open circles, frequency of Central American alleles, $y_{c a}$ (deduced). Open squares, frequency of West Colombian alleles, $y_{w c}$ (deduced). Closed circles, total frequency of yellow hindwing bar alleles, $y_{t}=y_{c a}+y_{w c}$ (observed directly). For the purposes of this figure, it has been assumed that $H$. erato at Cana $(340 \mathrm{~km})$ has equal frequencies of $y_{c a}$ and $y_{w c}$. Bars represent binomial standard errors of $y_{t}$ allele frequencies $(\sqrt{p q} / n)$. If a sample was fixed, an approximate standard error was calculated by assuming that one of the alleles was of the other type.

hybrids have more recently dispersed across the $40 \mathrm{~km}$ straits from the mainland. The island frequency of the $y_{c a}$ allele is similar to the mainland frequency due $\mathrm{NE}$ at approx $150 \mathrm{~km}$ (fig. 4), suggesting that migrants may have been transported to the island by the strong NE trade winds which blow throughout the dry season.

Some minor phenotypic attributes also changed along the transect. The white distal wing fringes, characteristic of the West Colombian race, more or less follow the pattern of the $y_{w c}$ alleles, both in $H$. erato and $H$. melpomene (fig. 5). However, vestiges of white fringes are regularly found far to the west of the hybrid zones of both species, where the $y_{w c}$ allele is never found. Other minor colour patterns which characterise the West Colombian race (blue iridescence, lack of basal red wing spots, and white head and thoracic markings) also penetrate further west than does the $y_{w c}$ allele. Size generally increases eastwards in $H$. erato, especially near the Colombian border, but remains approximately constant in $H$. melpomene (fig. 5).
Warning colour evolution in a hybrid zone: theoretical results. When $s_{1}$ and $s_{2}$ are non-zero, simulations clearly show that warning colour clines can form in which selection and migration interact to give a stable gradient. After stabilisation, the clines have a gradient of $0 \cdot 282 \sqrt{s} / \sigma$, assuming $s_{1}=s_{2}=s$. Providing dispersal is high $\left(\sigma^{2} / s>0.5\right.$, in units of deme spacing), the cline will move even when the selection on phenotypes is symmetric $\left(s_{1}=s_{2}\right)$. The reason for movement is that the selection on alleles is not symmetric due to dominance, so that the cline will advance at constant velocity until more and more of the area is fixed for the dominant allele. This kind of evolution can be termed "dominance drive". The cline will also move in the absence of dominance if selection is asymmetric. Alternatively, asymmetric selection can balance dominance drive so that the cline is stationary. An excess of migration in one direction, which can be caused by a population density gradient, will also move the cline at constant velocity (see also Barton, 1979). The three factors which 


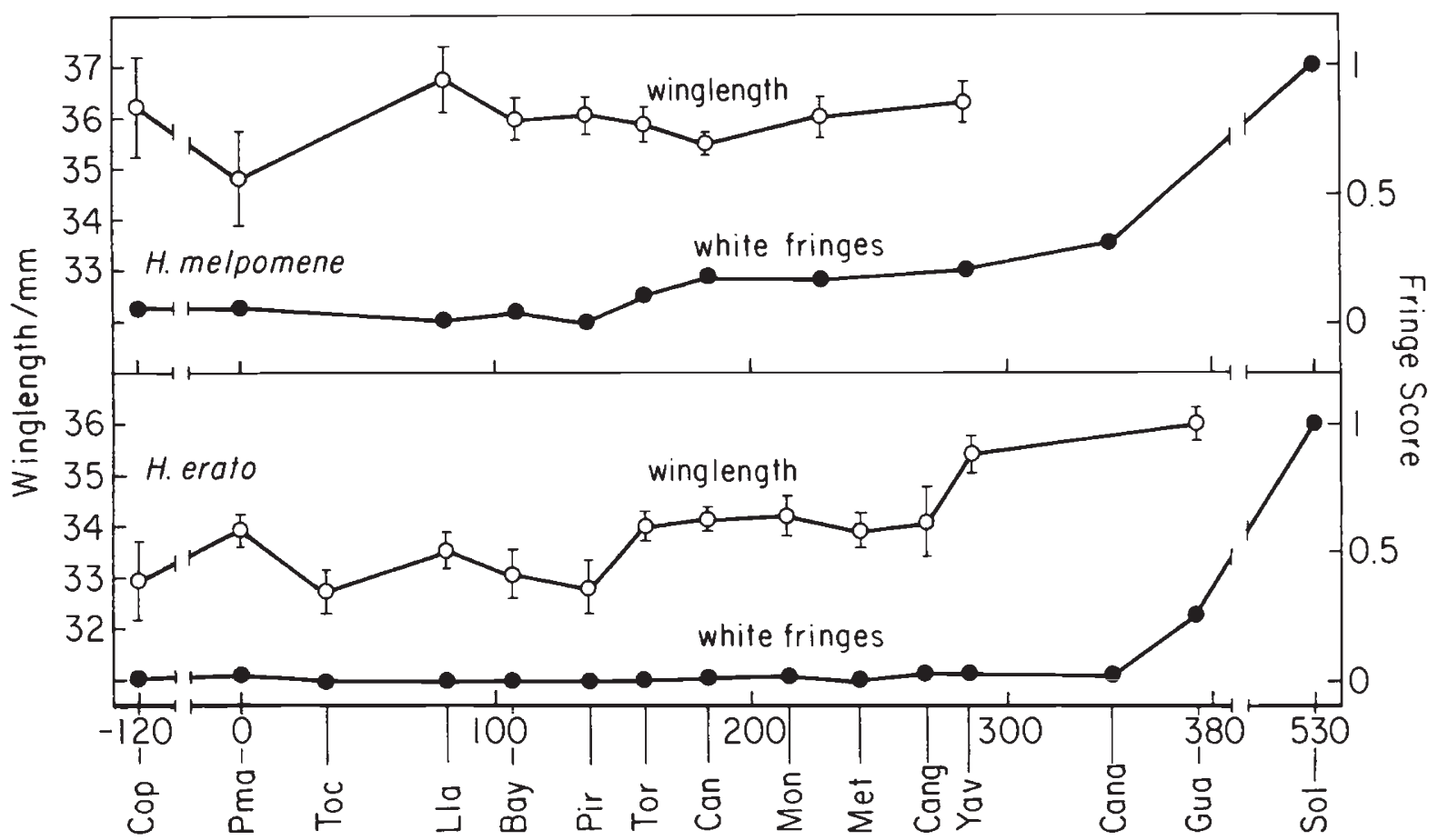

Figure 5 Minor phenotype changes along the transect. Bars represent errors of mean winglength.

cause movement-dominance drive, selection imbalance of phenotypes, and migration imbalance-can oppose each other to give stationary clines, but the stillness of these clines is neutrally stable. When there is no migration imbalance and $s_{1}=s_{2}=s$, dominance drive will move the cline at a speed given by $c=0 \cdot 1037 \sigma \sqrt{s}$. This corresponds to the case in $H$. erato where one colour pattern is not known to be inherently better at warning off predators than another, so that dominance drive alone moves the hybrid zone.

\section{DISCUSSION}

The width of the cline at $150 \mathrm{~km}$ in $H$. erato is about $80 \mathrm{~km}, 160$ times the gene flow parameter $(\sigma)$ estimated to be $0.15-0.5 \mathrm{~km}$ gen $^{-1 / 2}$ by Turner (1971b), Benson (1982), and Mallet (1984, 1985). This suggests that selection is very low, or that dispersal distance has been underestimated, or both (Endler, 1977). Alternatively, the genes for colour pattern are nearly neutral, and the cline has been slowly decaying in slope since secondary contact occurred. If there is no selection, and the hybrid zone is due to secondary contact, the rate of increase of cline width is calculable. I have found that $\sigma=0.293 \mathrm{~km}$ gen. ${ }^{-1 / 2}$ (Mallet, 1984, 1985) for $H$. erato, and the width, $w$, of the hybrid zone is $80 \mathrm{~km}$. The number of generations required to obtain a cline this wide from secondary contact is $0 \cdot 35(w / \sigma)^{2}$ (Endler, 1977:93), approximately 26,000 generations. Since the mean generation time of $H$. erato is about 3 months, if the yellow hindwing bar were selectively neutral, the hybrid zone would be about 6500 years old. This corresponds rather well with the expected time of refugia formation, about 10,000 years b.p. (Turner, 1982; Brown, 1982). However, even with low selection pressures the gradient stabilises quickly in simulations. The strong geographic correlation between $H$. erato and $H$. melpomene colour patterns strongly suggests that selection is acting on colour pattern, and experiments have confirmed this (Brower et al., 1963; Brower and Brower, 1964; Benson, 1972).

If the $H$. erato cline at $150 \mathrm{~km}$ is at migrationselection equilibrium, the parameter $s$ can be estimated from the field-measured parameters of cline slope and $\sigma$, using the simulation results. If $\sigma=$ $0.293 \mathrm{~km}$ gen. ${ }^{-1 / 2}$ then a hybrid zone with slope $1 / 80 \mathrm{~km}^{-1}$ will be produced if $s_{1}=s_{2}=0.0002$. This seems an incredibly low maximum selection pressure for warning colour and suggests that $\sigma$ has been underestimated. There is some reason to believe that my dispersal measure is an underestimate (Mallet, 1984, unpubl.). But supposing these estimates were correct, the cline would move (assuming $s_{1}=s_{2}$ ) at about $0.0004 \mathrm{~km} \mathrm{gen}^{-1}$ by means of dominance drive, or about $1.6 \mathrm{~km}$ per 
millennium. (If $s_{1}$ and $s_{2}$ are not equal, movement could be more or less rapid: I am here using dominance drive as an indicator of the cline's tendency to move.) This snail's pace is hardly likely to be important, even in geological time, and almost any stochastic or historical forces would be expected to have much greater effect.

On the other hand, Benson's (1972) field study of the value of warning colour in $H$. erato gives a much higher selection pressure. Benson radically altered the colour pattern of the Central American race by painting over the red forewing band with black paint. If longevity is proportional to fitness, then Benson's data suggest that $s$ is approximately $0 \cdot 21$, so the observed gradient at $150 \mathrm{~km}$ (fig. 4) could be explained if $\sigma$ was about $10 \mathrm{~km}$ gen. ${ }^{-1 / 2}$. A hybrid zone with $s_{1}=s_{2}=s$ under these conditions would move at a rate of about $0.5 \mathrm{~km}$ gen. ${ }^{-1}$, or about $2000 \mathrm{~km}$ per millennium. Here selection and migration might seem to be unrealistically high for the yellow hindwing bar cline, but, if the parameters were as estimated, dominance drive would cause very rapid movement on a geological time scale, and could be very important in generating warning colour pattern evolution in $H$. erato. Keith Brown (pers. comm.) indicates that $\sigma=10 \mathrm{~km}$ gen. $^{-1 / 2}$ may be realistic for $H$. erato.

Which of these two estimated results is nearer the truth depends on which parameter measurements are more nearly correct. If dispersal and selection are low, then only slow movement is possible, and it seems likely that most parapatric distributions of $\mathrm{H}$. erato colour patterns origina. by means of secondary contact after races expanded from core refugia in which differentiation took place. If, on the other hand, selection is intense and dispersal is considerable, then even if hybrid zones were generated by secondary contact, rapid cline movements could easily have obscured any patterns generated as long as 10,000 years ago. A third possibility is that very little movement will occur even if the tendency to move is high, because density gradients and patchy population structure can act as dispersal barriers which tend to stop cline movements (Barton, 1979).

Size and minor coloration differences across the zones (fig. 5) are likely to be under selection, since $H$. erato and $H$. melpomene vary in parallel for these elements. Genes for these minor phenotypic traits may be coadapted or linked to the major colour pattern locus. Different gene frequency clines will remain together, especially if coadapted or linked (Barton and Hewitt, 1981; Slatkin, 1975). Since they have less phenotypic effect, minor colour pattern elements might be expected to have gene frequency "tails" that are longer than the tails of the major elements, as was observed (see Results and fig. 5).

In conclusion, this study shows that Heliconius hybrid zones might move fast enough to obscure distribution patterns initiated in Pleistocene refugia. The theory also suggests an alternative model for race formation in Heliconius. New warning colour patterns might occasionally evolve within the range of a species by means of genetic drift (Mallet, 1984, 1985), kin selection (Harvey and Greenwood, 1978; Harvey et al., 1982), or group selection (Eshel, 1972). The new pattern would be able to spread behind a moving hybrid zone if selection, dominance and density gradients are favourable. This is essentially a shifting balance (Wright, 1982) theory of warning colour pattern evolution, consisting of a phase of local genetic drift followed by a phase of interdemic spread. The model is similar to the stasipatric theory of chromosomal evolution (White, 1978; Wright, 1978 ) in that alternative fixations of a few genes are the "adaptive peaks". Better measurements of selection and population structure are needed to evaluate this idea, which can be used as an alternative hypothesis in testing for the effect of Pleistocene refugia on race formation in Heliconius.

Acknowledgements I thank Nick Barton, Paul Brakefield, Keith Brown, John Endler, Larry Gilbert, Paul Harvey, Godfrey Hewitt, Sandra Knapp, Jack Longino, Bob Silberglied, Beryl Simpson, Gordon Small, John Smiley, John Turner, Marcy Uyenoyama, Don Windsor and Janet Young for their help during this project. This project was funded by a grant from the Educational Outreach Fund of the Smithsonian Tropical Research Institute.

\section{REFERENCES}

BARTON, N. H. 1979. The dynamics of hybrid zones. Heredity, 43, 341-359.

BARTON, N. H. AND HEWITT, G. M. 1981. Hybrid zones and speciation. In Evolution and Speciation. Essays in Honour of M.J.D. White, W. R. Atchley, and D. Woodruff (eds), pp. 109-145. Cambridge Univ. Press, Cambridge.

BAZYKIN, A. D. 1969. Hypothetical method of speciation. Evolution, 23, 685-687.

BENSON, W. W. 1972. Natural selection for Müllerian mimicry in Heliconius erato in Costa Rica. Science, 176, 936-939.

BENSON, W. W. 1982. Alternative models for infrageneric diversification in the humid tropics: tests with passion vine butterflies. In Biological Diversification in the Tropics, G. T. Prance (ed), pp. 608-640. Columbia Univ. Press, New York.

BoGGS, C. L. 1979. Resource allocation and reproductive strategies in several heliconiine butterfly species. Ph.D. Thesis, Univ. Texas, Austin.

BROWER, L. P. AND BROWER, J. VAN Z. 1964. Birds, butterflies and plant poisons: a study in ecological chemistry. Zoologica, N.Y., 49, 137-159. 
BOWER, L. P., BROWER, J. VAN Z, AND COLLINS, C. T. 1963. Experimental studies of mimicry. 7. Relative palatability and Müllerian mimicry among Neotropical butterflies of the subfamily Heliconiinae. Zoologica, N.Y., 48, 65-84.

BROWN, K. S. 1976. Geographical patterns of evolution in Neotropical Lepidoptera. Systematics of known and new Heliconiini (Nymphalidae: Nymphalinae). J. Entomol. (B), 44, 201-242.

BROWN, K. S. 1979. Ecologia Geográfica e Evolucào nas Florestas Neotropicais. Universidade Estadual de Campinas, Brazil.

BROWN, K. S. 1981. The biology of Heliconius and related genera. Ann. Rev. Entomol., 26, 427-456.

BROWN, K. S. 1982. Paleoecology and regional patterns of evolution in neotropical forest butterflies. In Biological Diversification in the Tropics, G.T. Prance (ed), pp. 255-308. Columbia Univ. Press, New York.

BROWN, K. S. AND MIELKE, O. H. H. 1972. The heliconians of Brazil (Lepidoptera: Nymphalidae). Part II. Introduction and general comments with a supplementary revision of the tribe. Zoologica, N.Y., 57, 1-40.

BROWN, K. S., SHEPPARD, P. M. AND TURNER, J. R. G. 1974. Quaternary refugia in tropical America: evidence from race formation in Heliconius butterflies. Proc. Roy. Soc. Lond. B., $187,369-378$.

DESCIMON, H. AND MAST DE MAEGHT, J. 1984. Semispecies relationships between Heliconius erato cyrbia Godt. and $H$. himera Hew. in southwestern Ecuador. J. Res. Lepidop., 22, 229-237.

EMSLEY, M. G. 1964. The geographical distribution of colour pattern components of Heliconius erato and Heliconius melpomene. Zoologica, N.Y., 49, 245-286.

ENDLER, J. A. 1977. Geographic Variation, Speciation, and Clines. Princeton Univ. Press, Princeton, NJ.

ENDLER, J. A. 1982. Pleistocene forest refuges: fact or fancy? In Biological Diversification in the Tropics, G. T. Prance (ed), pp. 641-657. Columbia Univ. Press, New York.

ESHEL, I. 1972. On the neighbor effect and the evolution of altruistic traits. Theoret. Popul. Biol., 3, 258-277.

FELSENSTEIN, J. 1976. The theoretical population genetics of variable selection and migration. Ann. Rev. Genet. 10, 253-280.

HADELER, K. P. 1976. Traveling population fronts. In Population Genetics and Ecology, S. Karlin and E. Nevo (eds), pp. 585-592. Academic Press, N.Y.

HARVEY, P. H., BULl, J. J., PEMBERTON, M. AND PAXTON, R. J. 1982. The evolution of aposematic coloration in distasteful prey: a family model. Amer. Natur., 119, 710-719.

HARVEY, P. H., BULL, J. J., PEMBERTON, M. AND PAXTON, R. J. 1982. The evolution of aposematic coloration in distasteful prey: a family model. Amer. Natur., $119,710-719$.

HARVEY, P. H. AND GREENWOOD, P. J. 1978. Anti-predator defence strategies: some evolutionary problems. In Behavioural Ecology, J. R. Krebs and N. B. Davies (eds), pp. 129-151. Blackwell, Oxford.

LEWONTIN, R. C. AND COCKERHAM, C. C. 1959. The goodnessof-fit test for detecting natural selection in random-mating populations. Evolution, 13, 561-564.

MACARTHUR, R. H. 1972. Geographical Ecology. Harper and Row, N.Y.

MALleT, J. 1984. Population structure and evolution of Heliconius butterflies. Ph.D. Thesis, Univ. Texas, Austin.

MALLET, J. 1985. Dispersal and gene flow in a butterfly with home range behaviour: Heliconius erata (Lepidoptera: Nymphalidae) Oecologia (in press).

MAYR, E. 1970. Populations, Species and Evolution. Belknap Press, Cambridge, Mass.
SHEPPARD, P. M. 1963. Some genetic studies of Müllerian mimics in butterflies of the genus Heliconius. Zoologica, N.Y., 48, 145-154.

SHEPPARD, P. M., TURNER, J. R. G., BROWN, K. S., BENSON, W. W. AND SINGER, M. C. 1985. Genetics and the evolution of muellerian mimicry in Heliconius butterflies. Phil. Trans. Roy. Soc. Lond. B., 308, 433-613.

SLATKIN, M. 1975. Gene flow and selection in a two-locus system. Genetics, 81, 787-802.

STOKES, A. N. 1976. On two types of moving front in quasilinear diffusion. Math. Biosci., 31, 307-315.

TURNER, J. R. G. 1965. Evolution of complex polymorphism and mimicry in distasteful South American butterflies. Proc. XII Int. Cong. Entomol. London 1964, 267.

TURNER, J. R. G. $1971 a$. Two thousand generations of hybridization in a Heliconius butterfly. Evolution, 25, 471-482.

TURNER, J. R. G. $1971 b$. Experiments on the demography of tropical butterflies. II. Longevity and home-range behaviour in Heliconius erato. Biotropica, 3, 21-31.

TURNER, J. R. G. 1972. The genetics of some polymorphic forms of the butterflies Heliconius melpomene Linnaeus and Heliconius erato Linnaeus. II. The hybridization of subspecies of $H$. melpomene from Surinam and Trinidad Zoologica, N.Y., 56, 125-157.

TURNER, J. R. G. 1974. Breeding Heliconius in a temperate climate. J. Lepid. Soc., 28, 26-33.

TURNER, J. R. G. 1981. Adaptation and evolution in Heliconius. A defense of neoDarwinism. Ann. Rev. Ecol. Syst., 12, 99-121.

TURNER, J. R. G. 1982. How do refuges produce biological diversity? In Biological Diversification in the Tropics, G. T. Prance (ed), pp. 309-355. Columbia Univ. Press, New York.

TURNER, J. R. G. AND CRANE, J. 1962. The genetics of some polymorphic forms of the butterflies Heliconius melpomene Linnaeus and Heliconius erato Linnaeus. I. Major genes. Zoologica, N.Y., 47, 141-152.

TURNER, J. R. G., JOHNSON, M. S. AND EANES, W. F. 1979. Contrasted modes of evolution in the same genome: allozymes and adaptive change in Heliconius. Proc. Nat. Acad. Sci. USA, 76, 1924-1928.

WAllace, B. 1968. Topics in Population Genetics. Norton, New York.

WhITE, M. J. D. 1978. Modes of Speciation. Freeman, San Francisco, Calif.

WRIGHT, S. 1978. Review of "Modes of Speciation", by M. J. D. White. Paleobiology, 4, 373-379.

WRIGHT, S. 1982. Character change, speciation, and the higher taxa. Evolution, 36, 427-433.

\section{APPENDIX 1: PARTITIONING OF $y_{w c}$ AND $y_{c a}$}

The frequency $\left(y_{w c}+y_{c a}\right)$ can be estimated directly, but, in order to partition the alleles $y_{w c}$ and $y_{c a}$, Hardy-Weinberg equilibrium between the two must be assumed. Then, using the method of maximum likelihood:

$$
\frac{p\left(y_{c a}\right)}{p\left(y_{w c}\right)}=\frac{f_{D}+f_{D}\left(f_{D}+f_{C}\right)}{f_{C}}
$$

(M. Uyenoyama, pers. comm.)

where $p\left(y_{w c}\right)$ and $p\left(y_{c a}\right)$ represent the frequencies of alleles $y_{w c}$ and $y_{c a}$; and $f_{A}, f_{B}, f_{C}, f_{D}$ represent the frequencies of phenotypes $A, B, C$ and $D$. 